\title{
Clinical Utility Gene Card for: autosomal dominant myotonia congenita (Thomsen Disease)
}

\author{
David J. Coote ${ }^{1}$ Mark R. Davis ${ }^{2} \cdot$ Macarena Cabrera $^{3} \cdot$ Merrilee Needham $^{4} \cdot$ Nigel G. Laing $^{1,2} \cdot$ Kristen J. Nowak $^{1,5,6}$
}

Received: 18 January 2017 / Revised: 28 September 2017 / Accepted: 23 November 2017 / Published online: 26 April 2018

(c) European Society of Human Genetics 2018

\section{Disease characteristics}

\subsection{Name of the disease (synonyms)}

Myotonia congenita, autosomal dominant (Thomsen disease; THD).

\subsection{OMIM\# of the disease}

160800.

\subsection{Name of the analysed genes or DNA/ chromosome segments}

Skeletal muscle chloride channel-1 (CLCN1).

Kristen J. Nowak

kristen.nowak@health.wa.gov.au

1 Centre for Medical Research, Faculty of Health and Medical Sciences, The University of Western Australia; and Harry Perkins Institute of Medical Research, QQ Block, QEII Medical Centre, Nedlands, WA 6009, Australia

2 Neurogenetics Laboratory, Department of Diagnostic Genomics, PP Block, QEII Medical Centre, Nedlands, WA 6009, Australia

3 Department of Neurology and Instituto de Biomedicina de Sevilla, Hospital Universitario Virgen del Rocío, Seville 41013, Spain

4 Western Australian Neuroscience Institute, QEII Medical Centre, Nedlands, Western Australia 6009; Fiona Stanley Hospital, 11 Robin Warren Drive, Murdoch, WA 6150, Australia

5 School of Biomedical Sciences, Faculty of Health and Medical Sciences, The University of Western Australia, Crawley, WA, Australia

6 Office of Population Health Genomics, Public and Aboriginal Health Division, Department of Health, East Perth, WA 6004, Australia

\subsection{OMIM\# of the gene(s)}

118425.

\subsection{Mutational spectrum}

Myotonia congenita is a genetic disease of skeletal muscle membrane hyperexcitability caused by variants in $C L C N 1$, leading to reduced conductance of the main skeletal muscle chloride channel (ClC-1) [1]. This disorder can be inherited in an autosomal dominant (Thomsen disease; sometimes associated with reduced penetrance) or recessive (Becker disease; OMIM 255700) fashion. Thomsen disease is rare and exhibits a high degree of genetic heterogeneity.

The following variant types in CLCN1 have been reported: missense, nonsense, long deletions/duplications, insertions/deletions (indels), combined indels, and splice site [2]. The majority of Thomsen disease variants are missense [3] and a hotspot has been reported in exon 8 , which codes for a region of interaction between ClC-1 monomers [4]. Over 200 CLCN1 variants have been identified as affecting chloride channel function (dominant and recessive inheritance), and a regularly updated database exists (available at: http://chromium. lovd.nl/LOVD2/variants.php?select_db $=$ CLCN1\&action $=$ view_unique).

\subsection{Analytical methods}

Sequencing of all 23 coding exons in CLCNI by Sanger or massively paralleled sequencing methods is successful in identifying $>95 \%$ of variants. Large deletions and duplications ( $<5 \%$ of cases) [5] can be assessed through the multiplex ligation-dependent probe amplification technique (MLPA) or other exon copy number detection methods. 


\subsection{Analytical validation}

Putative variants identified through massively paralleled sequencing methods can be validated by Sanger sequencing, although this is not common practise in all diagnostic laboratories. Verification of a single exon duplication or deletion should occur via different methodology to eliminate the contribution of possible technique-specific artefacts and the complication of rare sequence variants affecting the efficacy of probe binding [6].

\subsection{Estimated frequency of the disease}

(Incidence at birth ("birth prevalence") or population prevalence. If known to be variable between ethnic groups, please report):

Estimated at 1 in 100,000 people worldwide [7, 8], with a higher frequency of 7.3 or 9.0 per 100,000 in Northern Finland and Northern Norway respectively (see below) [2, 9]. CLCNl variants have been enriched in Northern Finland due to founder effects and geographical isolation [10]. There is a similarly elevated prevalence in Northern Norway, but with a greater degree of genotypic heterogeneity [9].

\subsection{Diagnostic setting}

\begin{tabular}{ll}
\hline A. (Differential) diagnosis & Yes. \\
B. Predictive Testing & C. Risk assessment in Relatives \\
D. Prenatal & $\square$
\end{tabular}

\section{Comment:}

Myotonia is a prominent finding in numerous diseases, leading to diagnostic difficulty [11]. Paramyotonia congenita (OMIM 168300), potassium-aggravated myotonia (OMIM 608390) and myotonic dystrophy type 1 (OMIM 160900) and type 2 (OMIM 602668) should be considered when making a differential diagnosis. Thomsen disease can usually be distinguished from these other disorders based on the following: factors that aggravate or alleviate myotonia, such as repetitive small skeletal muscle contractions alleviating stiffness in Thomsen disease; [11, 12] absence of extramuscular symptoms such as early cataracts; and electromyography results following refined exercise testing [13]. Distinguishing between autosomal recessive and autosomal dominant myotonia congenita usually relies on a family history, as variants may be associated with both modes of inheritance. However a more severe presentation tends to occur from autosomal recessive variants [14].

Presymptomatic testing of at risk individuals can be appropriate but does not offer an accurate prediction of disease phenotype (age of onset, severity, progression, etc).

\section{Test characteristics}

$\begin{aligned} & \text { Genotype or A: True positives } \\ & \text { disease }\end{aligned}$ False
negative

Present Absent B: False positives D: True

negative

Test

\begin{tabular}{|c|c|c|c|}
\hline \multirow[t]{2}{*}{ Positive $A$} & B & Sensitivity: & $\mathrm{A} /(\mathrm{A}+\mathrm{C})$ \\
\hline & & Specificity & $\mathrm{D} /(\mathrm{D}+\mathrm{B})$ \\
\hline \multirow[t]{2}{*}{ Negative $\mathrm{C}$} & $\mathrm{D}$ & $\begin{array}{l}\text { Positive predic- } \\
\text { tive value }\end{array}$ & $\mathrm{A} /(\mathrm{A}+\mathrm{B})$ \\
\hline & & $\begin{array}{l}\text { Negative predic- } \\
\text { tive value }\end{array}$ & $\mathrm{D} /(\mathrm{C}+\mathrm{D})$ \\
\hline
\end{tabular}

\subsection{Analytical sensitivity (proportion of positive tests if the genotype is present)}

Close to $100 \%$.

\subsection{Analytical specificity (proportion of negative tests if the genotype is not present)}

Close to $100 \%$.

\subsection{Clinical sensitivity (proportion of positive tests if the disease is present)}

The clinical sensitivity can be dependent on variable factors such as age or family history. In such cases a general statement should be given, even if a quantification can only be made case by case.

CLCN1 is the only gene associated with Thomsen disease, and so in most cases it is relatively straightforward to identify a causative variant if an accurate clinical diagnosis has been made. However, there are several disorders that can be mistaken for Thomsen disease (see 1.9). A multigene panel including $C L C N 1$ can be considered for screening in ambiguous cases.

\subsection{Clinical specificity (proportion of negative tests if the disease is not present)}

The clinical specificity can be dependent on variable factors such as age or family history. In such cases a general 
statement should be given, even if a quantification can only be made case by case.

The clinical specificity is high. However some dominant variants can be associated with reduced penetrance (even if family members with the same variant have a severe phenotype), resulting in a positive genetic test when the disease phenotype is and will remain absent [15].

\subsection{Positive clinical predictive value (life time risk to develop the disease if the test is positive)}

Several clinical variants of Thomsen diseases can arise from autosomal dominant $C L C N 1$ variants. Fluctuating myotonia congenita [16] and myotonia levior [17] differ from Thomsen disease in their age of onset and associated symptomatology [15]. Considering all dominant chloride channelopathy variants as a whole, the positive clinical predictive value is still below $100 \%$ due to reduced penetrance.

\subsection{Negative clinical predictive value (probability not to develop the disease if the test is negative)}

Assume an increased risk based on family history for a nonaffected person. Allelic and locus heterogeneity may need to be considered.

Index case in that family had been tested:

$100 \%$.

Index case in that family had not been tested:

Close to $100 \%$.

\section{Clinical utility}

\section{1 (Differential) diagnostics: The tested person is clinically affected}

(To be answered if in 1.9 "A" was marked)

\subsubsection{Can a diagnosis be made other than through a genetic test?}

No. $\bigotimes$ Alternative diagnostic methods can help guide genes causing non-dystrophic myotonias), however ident CLCN1 is considered the only definitive diagnosis of Thor Yes.

clinically.

imaging.

endoscopy.

biochemistry.

electrophysiology.

other (please describe):

\subsubsection{Describe the burden of alternative diagnostic methods to the patient}

Particular phenotypic characteristics of Thomsen disease are simple to test for, however mutational analysis is required to reach a definitive diagnosis. Thomsen disease usually onsets at a young age (infancy through childhood) with myotonia, which is delayed skeletal muscle relaxation. Myotonia often presents following contraction after a prolonged period of rest (e.g., arising from a chair/bed, or starting to walk or run) [15] and improves upon repeated skeletal muscle contraction, the so called "warm-up phenomenon" [15]. Conversely, in paramyotonia congenita the symptoms typically worsen with repeated skeletal muscle contraction [11].

Myotonia with (1) severe cold sensitivity, (2) obvious potassium sensitivity, or (3) pain are common in sodium channelopathies and less common in chloride channelopathies [15]. These clinical features can be useful in directing confirmatory genetic testing. Myotonia of the eyelids can be present in both chloride and sodium channelopathies [18]. Muscle hypertrophy resulting in an athletic appearance is a characteristic feature of some myotonias, presumably because individuals experience involuntary prolonged skeletal muscle contraction [15].

Thomsen disease and other non-dystrophic myotonias are normally distinguished from myotonic dystrophy because of the absence of systemic features and permanent weakness in the former. However, in some instances, particularly in myotonic dystrophy 2 , other systemic features can be absent, and skeletal muscle weakness can be subtle or absent. In this situation, a skeletal muscle biopsy would help in the differential diagnosis by showing dystrophic changes, and other specific histopathological features of each condition. Skeletal muscle biopsies of non-dystrophic myotonias typically appear normal, although an absence or reduction in type $2 \mathrm{~B}$ fibres in some patient biopsies has been noted [19].

Electrophysiological exercise tests can also aid in diagnosis, but results are not always conclusive in channelopathies [13]. An electromyography (EMG) would be useful to confirm the presence of electrical myotonia in patients with mild symptoms for whom the examination fails to demonstrate it. A needle EMG, and more so skeletal muscle biopsy collection, could be regarded invasive procedures and therefore their usefulness in facilitating a molecular diagnosis needs to be considered.

3.1.3 How is the cost effectiveness of alternative diagnostic methods to be judged?

Genetic testing is required for a definitive diagnosis, so any alternative diagnostic method would be additional in cost. 
However, if a method of screening multiple genes at once is not available (e.g., a multi-gene panel, or whole exome sequencing), then results from complementary diagnostic tests may help direct molecular screening to the CLCN1 gene and thus could be cost and time effective depending on price.

3.1.4 Will disease management be influenced by the result of a genetic test?

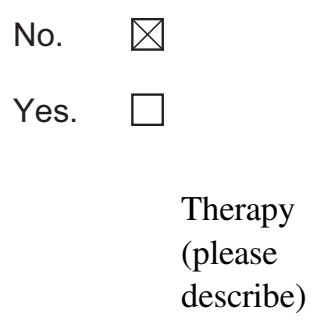

Thomsen disease is only pharmacologically treated in severe cases and no genetic treatments exist. Therefore the result of a genetic test is not essential for current treatment options. Mexiletine (antiarrhythmic agent) is the bestdocumented treatment option for nondystrophic myotonia [15]. However, the only largescale, placebo-controlled clinical trial reporting its benefits did not differentiate between chloride and sodium channelopathies [20]. Other medications such as sodium channel blockers, antiepileptic agents, antidepressants, diuretics and taurine have not been supported by sufficient high quality clinical trials to asses efficacy or safety [15, 21].

There are, however, anecdotal reports of significant benefit from the above therapies [15]. Other novel therapies for dystrophic [22, 23] and nondystrophic [24] myotonias are at various stages of development. As some experimental therapies have a genetic basis, a genetic diagnosis may become an essential precursor to treatment in the future.
Table (continued)

$\begin{array}{ll}\begin{array}{l}\text { Prognosis } \\ \text { (please } \\ \text { describe) }\end{array} & \begin{array}{l}\text { There is presently a poor } \\ \text { understanding of the } \\ \text { genotype-phenotype relation- } \\ \text { ship within CLCN1. Genetic } \\ \text { testing is useful in identifying } \\ \text { the causative disease gene, but } \\ \text { knowledge of the } C L C N 1\end{array} \\ & \begin{array}{l}\text { variant does not further inform } \\ \text { disease prognosis. Lifespan is } \\ \text { typically normal. } \\ \text { The management of all myo- } \\ \text { Management } \\ \text { (please } \\ \text { describe) }\end{array} \\ & \begin{array}{l}\text { tonias consists of symptomatic } \\ \text { treatment as well as physical } \\ \text { therapy [15]. }\end{array} \\ \end{array}$

\subsection{Predictive setting: the tested person is clinically unaffected but carries an increased risk based on family history}

(To be answered if in 1.9 "B" was marked)

\subsubsection{Will the result of a genetic test influence lifestyle and prevention?}

If the test result is positive (please describe)

No preventative options are available. Thomsen disease is usually associated with a mild phenotype and thus has a relatively minimal effect on lifestyle [15]. General anaesthetic agents should be used with caution, with particular care taken in administration of depolarising muscle relaxants such as suxamethonium [25].

If the test result is negative (please describe)

No.

3.2.2 Which options in view of lifestyle and prevention does a person at-risk have if no genetic test has been done (please describe)?

As per 3.2.1, no preventative options are available so genetic testing does not influence this aspect. General anaesthetic agents should also be used with caution in atrisk individuals whose molecular diagnosis remains ambiguous.

\subsection{Genetic risk assessment in family members of a diseased person}

(To be answered if in 1.9 "C" was marked) 
3.3.1 Does the result of a genetic test resolve the genetic situation in that family?

A genetic test can identify a causative $C L C N 1$ variant/s, but does not alone resolve the mode of inheritance within a family. Some variants have been associated with both autosomal dominant and recessive inheritance, and thus a family history is required to differentiate between Thomsen and Becker myotonia congenitas [26].

\subsubsection{Can a genetic test in the index patient save genetic or other tests in family members?}

Yes. Genetic testing is not always necessary in patients with definitive clinical symptoms and a first degree family member with a positive genetic test [15].

\subsubsection{Does a positive genetic test result in the index patient enable a predictive test in a family member?}

Yes. However, predictive testing is not useful in predicting the age of onset, severity or progression of disease.

\subsection{Prenatal diagnosis}

(To be answered if in 1.9 "D" was marked)

\subsubsection{Does a positive genetic test result in the index patient enable a prenatal diagnosis?}

Yes, although prenatal testing in CLCN1 is uncommon. There may be some discrepancy among medical professionals and families regarding the use of prenatal testing with the intention of pregnancy termination due to the relatively mild disease phenotype and good prognosis. While most centres consider the option of prenatal testing a decision to be made by the family, it is appropriate that this issue be discussed during genetic counselling.

\section{If applicable, further consequences of testing}

Please assume that the result of a genetic test has no immediate medical consequences. Is there any evidence that a genetic test is nevertheless useful for the patient or his/her relatives? (Please describe)

An accurate genetic diagnosis often has a positive psychological effect on patients and their family, alleviating the anxiety associated with misunderstanding one's symptoms, or the symptoms of a family member. Genetic testing may play a more direct role in the future with the development of targeted myotonic therapies [22-24, 27].
Acknowledgements This work was supported by EuroGentest2 (Unit 2: "Genetic testing as part of health care"), a Coordination Action under FP7 (Grant Agreement Number 261469) and the European Society of Human Genetics. KJN was funded by an Australian Research Council Future Fellowship FT100100734, NGL by a National Health and Medical Research Council Principal Research Fellowship APP1002147, and MC by Instituto de Salud Carlos III (JR15/00042).

\section{Compliance with ethical standards}

Conflict of interest The authors declare that they have no conflict of interest.

\section{References}

1. Lossin C, George Jr AL. Ion channel diseases. In: Hall JC, Dunlap $\mathrm{JC}$, Friedmann $\mathrm{T}$, van Heyningen $\mathrm{V}$, editors. Advances in Genetics. Academic Press, San Diego; 2008. 63, p. 25-55.

2. Baumann P, Myllylä VV, Leisti J. Myotonia congenita in northern Finland: an epidemiological and genetic study. J Med Genet. 1998;35:293-96.

3. Tang C-Y, Chen T-Y. Physiology and pathophysiology of CLC-1: mechanisms of a chloride channel disease, myotonia. J Biomed Biotechnol. 2011;2011:685328.

4. Fialho D, Schorge S, Pucovska U, et al. Chloride channel myotonia: exon 8 hot-spot for dominant-negative interactions. Brain. 2007;130:3265-74.

5. Raja Rayan DL, Haworth A, Sud R, et al. A new explanation for recessive myotonia congenita: exon deletions and duplications in CLCN1. Neurology. 2012;78:1953-58.

6. Grimm T, Kress W, Meng G, Müller CR. Risk assessment and genetic counseling in families with Duchenne muscular dystrophy. Acta Myol. 2012;31:179-83.

7. Emery AE. Population frequencies of inherited neuromuscular diseases—a world survey. Neuromuscul Disord. 1991;1:19-29.

8. Pinessi L, Bergamini L, Cantello R, Tizio C. Myotonia congenita and myotonic dystrophy: descriptive epidemiological investigation in Turin, Italy (1955-1979). Neurol Sci. 1982;3:207-10.

9. Sun C, Tranebjaerg L, Torbergsen T, Holmgren G, Van Ghelue M. Spectrum of CLCN1 mutations in patients with myotonia congenita in Northern Scandinavia. Eur J Hum Genet. 2001;9:903-9.

10. Papponen H, Toppinen T, Baumann P. Founder mutations and the high prevalence of myotonia congenita in northern Finland. Neurology. 1999;53:297-302.

11. Matthews E, Fialho D, Tan SV, et al. The non-dystrophic myotonias: molecular pathogenesis, diagnosis and treatment. Brain. 2010;133:9-22.

12. Wang GK, Mitchell J, Wang SY. Block of persistent late $\mathrm{Na}^{+}$ currents by antidepressant sertraline and paroxetine. J Membr Biol. 2008;222:79-90.

13. Tan SV, Matthews E, Barber M, et al. Refined exercise testing can aid DNA-based diagnosis in muscle channelopathies. Ann Neurol. 2011;69:328-40

14. Arzel-Hezode M, Sternberg D, Tabti N, et al. Homozygosity for dominant mutations increases severity of muscle channelopathies. Muscle Nerve. 2010;41:470-77.

15. Heatwole CR, Statland JM, Logigian EL. The diagnosis and treatment of myotonic disorders. Muscle Nerve. 2013;47:632-48.

16. Wagner S, Deymeer F, Kurz LL, et al. The dominant chloride channel mutant G200R causing fluctuating myotonia: clinical findings, electrophysiology, and channel pathology. Muscle Nerve. 1998;21:1122-1128. 
17. Lehmann-Horn F, Mailander V, Heine R, George AL. Myotonia levior is a chloride channel disorder. Hum Mol Genet. 1995;4:1397-402.

18. Trip J, Drost G, Ginjaar HB, et al. Redefining the clinical phenotypes of non-dystrophic myotonic syndromes. J Neurol, Neurosurg. 2009;80:647-652.

19. Heene R, Gabriel RR, Manz F, Schimrigk K. Type 2B muscle fibre deficiency in myotonia and paramyotonia congenita. A genetically determined histochemical fibre type pattern? J Neurol Sci. 1986;73:23-30.

20. Statland JM, Bundy BN, Wang Y, et al. Mexiletine for symptoms and signs of myotonia in nondystrophic myotonia: a randomized controlled trial. Jama. 2012;308:1357-65.

21. Trip J, Drost G, van Engelen BG, Faber CG. Drug treatment for myotonia. Cochrane Database Syst Rev. 2006; 1:Cd004762.

22. Zhang W, Wang Y, Dong S, Choudhury R, Jin Y, Wang Z. Treatment of type 1 myotonic dystrophy by engineering site- specific RNA endonucleases that target $(\mathrm{CUG})_{(\mathrm{n})}$ repeats. Mol Ther. 2014;22:312-20.

23. Mulders SA, van Engelen BG, Wieringa B, Wansink DG. Molecular therapy in myotonic dystrophy: focus on RNA gain-offunction. Hum Mol Genet. 2010;19:R90-7.

24. Desaphy JF, Carbonara R, Costanza T, Conte Camerino D. Preclinical evaluation of marketed sodium channel blockers in a rat model of myotonia discloses promising antimyotonic drugs. Exp Neurol. 2014;255:96-102.

25. Bandschapp O, Iaizzo PA. Pathophysiologic and anesthetic considerations for patients with myotonia congenita or periodic paralyses. Paediatr Anaesth. 2013;23:824-33.

26. Colding-Jorgensen E. Phenotypic variability in myotonia congenita. Muscle Nerve. 2005;32:19-34.

27. Novak KR, Norman J, Mitchell JR, Pinter MJ, Rich MM, Sodium channel slow inactivation as a therapeutic target for myotonia congenita. Ann Neurol. 2015;77:320-32. 